\title{
Is the decadal variability in the tropical Atlantic a precursor to the NAO?
}

\author{
I. Wainer ${ }^{1}$, J. Servain ${ }^{2, *}$, and G. Clauzet ${ }^{3}$ \\ ${ }^{1}$ Universidade de São Paulo, São Paulo, Brazil \\ ${ }^{2}$ Institut de Recherche pour le Développement (IRD), UR182, Paris, France \\ ${ }^{3}$ ASA South America, Rua Purpurina 155, Cj 96, 05435-030, São Paulo, Brazil \\ * currently at: FUNCEME, Fortaleza, CE, Brazil
}

Received: 13 September 2007 - Revised: 6 November 2008 - Accepted: 26 November 2008 - Published: 12 December 2008

\begin{abstract}
In the past two decades climate research in the tropical Atlantic with respect to the inter-hemispheric gradient of sea surface temperature (SST) emphasized the predominance of decadal-scale variability. Our results show that this mode of variability is prevalent only for part of the last 130 -years record (the 1880s, the 1920s and, especially, the 1970s). There is a lag of a few months between the decadal variations of the inter-hemispheric gradient of SST and the decadal variability of the North Atlantic Oscillation (NAO). This seems to indicate that the 10 -year variability first develops in the tropics and then propagates polewards. The inter-hemispheric gradient of SST mode should be thought as episodic and not as a periodic oscillation.
\end{abstract}

Keywords. Meteorology and atmospheric dynamics (Climatology) - Oceanography: general (Climate and interannual variability) - Oceanography: physical (Air-sea interactions)

\section{Introduction}

The climatic variability of the tropical Atlantic Ocean is known as a superimposition of several periodic features at different time scales (e.g. Servain and Merle, 1993). The dominant frequency is the seasonal cycle, which is mainly related to the latitudinal displacement of the Inter-Tropical Convergence Zone (ITCZ). Sea surface temperature (SST) deviations from the seasonal cycle (i.e. "anomalies") are primarily driven by changes in surface winds (e.g. Servain and Legler, 1986). These changes result from local air-sea interaction associated with the latitudinal migration of the ITCZ, or remotely forced by external factors (e.g. variability associated with El Niño - Southern Oscillation - ENSO - in the

Correspondence to: I. Wainer

(wainer@usp.br)
Pacific Ocean, or the North Atlantic Oscillation - NAO as in the extra-tropical Atlantic).

Superimposed on the tropical Atlantic seasonal cycle are two known modes of coupled atmosphere-ocean variability: The first one is an equatorial mode similar to ENSO (Zebiak, 1993). This Equatorial mode is predominantly associated with ocean dynamics: changes in the trade wind system in the western Equatorial Atlantic basin causes the thermocline to adjust, which in turn impacts on the equatorial upwelling pattern. Kelvin waves are triggered and cross the Atlantic basin in few weeks. These waves are reflected as Rossby waves or trapped at the African coast propagating polewards generating a higher latitude east-west response. Although weaker than the ENSO, the Atlantic equatorial SST mode is associated with anomalous variations in the zonal equatorial slope of the thermocline.

The second mode of variability, which is the focus of the present paper, is characterized by a north-south interhemispheric gradient in SST with associated changes in trade wind system of both hemispheres. It results from complex thermodynamics exchanges at the sea surface. Indeed, surface evaporation, a function of both SST and wind speed, is the predominant manner in which the tropical oceans balance incoming solar radiation. If the SST north of the equator becomes slightly warmer than to the south the sea level pressure gradient will drive southerly winds across the equator. The Coriolis force acts to turn these winds westward and eastward (south and north, respectively) of the equator. Superimposed on the background easterly trades south of the equator, these anomalous southeasterlies increase surface wind speed and hence evaporative cooling. Conversely, north of the equator wind speed and surface evaporation decrease, amplifying the initial northward SST gradient. This wind-evaporationSST (WES) feedback offers an explanation for the observed cross-equatorial differences in both wind speed and SST (Xie and Philander, 1994).

Published by Copernicus Publications on behalf of the European Geosciences Union. 
The inter-hemispheric SST gradient mode is of considerable influence with respect to the rainy season (FMAM) of the Northeast region of Brazil (known as Nordeste; Hastenrath and Heller, 1977; Moura and Shukla, 1981; Wainer and Soares, 1997). It also has some impact on the rainy season (JAS) in the Sahel region of West Africa as shown by Wagner, 1996. It is also known for not having a counterpart in the Pacific Ocean and will be referred to hereafter as IHSSTmode. This mode oscillates at several time scales ranging from seasonal-to-decadal.

Diagnostic studies from observations and numerical results indicate that the two interannual modes (equatorial and inter-hemispheric) seem to be related (e.g. Servain et al., 1999; Murtugudde et al., 2001; Servain et al., 2003; Ayina and Servain, 2003). In the past decades, considerable effort has been made to identify preferred periodicities in the regional rainfall variability and the associated large-scale circulation. Several studies pointed out the decadal nature of the inter-hemispheric SST mode (Servain, 1991; Servain and Merle, 1993; Mehta and Delworth, 1995; Mehta, 1998; Nobre and Shukla, 1996; Tanimoto and Xie, 1999; Ayina and Servain, 2003). A marked preference for variability around 11-13 years has also been indicated by Wainer and Soares (1997), Hastenrath and Kaczmarczyk (1981) and Chu (1984). On the other hand, Penland and Matrosova (1998) discussed that the variation of the interhemispheric SST gradient may not have preferred time scales.

The inter-hemispheric SST gradient mode, may have a pattern of SST anomalies of opposite sign on either side of the Equator, which shows up as one of the leading two EOFs of tropical Atlantic SSTs. It also appears from joint analyses of SST and surface winds, and it exhibits considerable variability on time scales of $8-16$ years. However, in such analyses, the leading EOFs are not well separated, so the possibility of degeneracy and effective mixing of modes exists. Indeed, rotated EOF analyses of tropical Atlantic SSTs yield discernibly different results from their unrotated counterparts. In particular, the results suggest that most of the variance in SST north and south of the ITCZ is not correlated at zero lag. Simple one-point correlation maps show little evidence of a dipole structure in the original SST data. In fact, tropical North and South Atlantic SST anomalies of opposite sign occur no more frequently ( $15 \%$ occurrence rate) than expected by chance. This does not mean, however, that significant fluctuations in the cross-equatorial SST gradient do not occur, nor that such fluctuations are unimportant. Analyses of historical instrumental SST records show that significant meridional gradients, in the absence of dipoles, occur in nearly $50 \%$ of all months over the tropical Atlantic.

A strong limitation in most of the previous studies in their representation of the decadal signal from SST observations over the tropical Atlantic basin, is that they refer to a temporal record of only a few decades, with the exception of Mehta, 1998, that examined 110 years of historical data but still, only until 1990. Nonetheless, the decadal signal is prominent be- tween the the years 1960-1990 (e.g. Servain, 1991). It seems however that such a decadal signal does not occur beyond the 1990s (Bourlés et al., 2008), which implies a question with respect to its permanence. The well documented decadal scale of the IHSST-mode is shown to exist for only a limited period (approximately 30 years) of the temperature record.

The present study aims to revisit the reality of the decadal frequency of the IHSST-mode using the largest presently available time series of SST thanks to the new data base (ERSST.v2) prepared by Smith and Reynolds (2004) and relate to other climate indices, in particular the NAO.

\section{Data and analysis}

Changes in the decadal-like variability of the IHSST-mode are examined through wavelets analysis applied to the last updated version of the Smith and Reynolds (2004) SST data base. The time series covers the period 1870-2004 that corresponds to approximately thirteen 10 -year cycles, a number definitely higher than for the previous studies. In order to elucidate possible mechanisms responsible for these changes, other global and regional climate indices are also examined using the same technique. These indices are those of ENSO, NAO and Northeast Brazil Rainfall, NEBR (as referred to in the Climate Diagnostic Bulletin: www.cpc.noaa. gov/products/analysis_monitoring/bulletin).

Wavelet analysis is an important addition to standard signal analysis methods. Unlike Fourier analysis which yields an average amplitude and phase for each harmonic in a data set, the wavelet transform produces an "instantaneous" estimate or local value for the amplitude and phase of each harmonic. This allows detailed study of non stationary spatial or time dependent signal characteristics. In other words, the wavelet technique permits examination of the resulting information in terms of time and frequency modes, decomposing the signals into localized oscillations. Furthermore, it also permits the characterization of the local regularity of signals. More details and description of wavelets together with the specific approach used in this investigation can be found in Torrence and Compo (1998).

A rough measure of the meteorological equator is the region of maximum of SST (Fig. 1). This domain migrates meridionally in the course of the year. Its northern and southern limits are reached at the end of each extreme season, that is, in March and September respectively (Hastenrath and Lamb, 1977; Servain and Lukas, 1990). For the Atlantic Ocean the meridional shift of the warm waters is generally a little larger in the western (from $10^{\circ} \mathrm{N}$ to $5^{\circ} \mathrm{S}$ ) than in the eastern (from $12^{\circ} \mathrm{N}$ to $0^{\circ}$ ) part of the basin. However, averaged over the year and all longitudes, the latitude of $5^{\circ} \mathrm{N}$ can be regarded as a suitable representation of the thermal equator (Fig. 1), and, according to Servain (1991), that limit is used here to demarcate the northern and southern basins, hereafter referred to as NB and SB, respectively. 


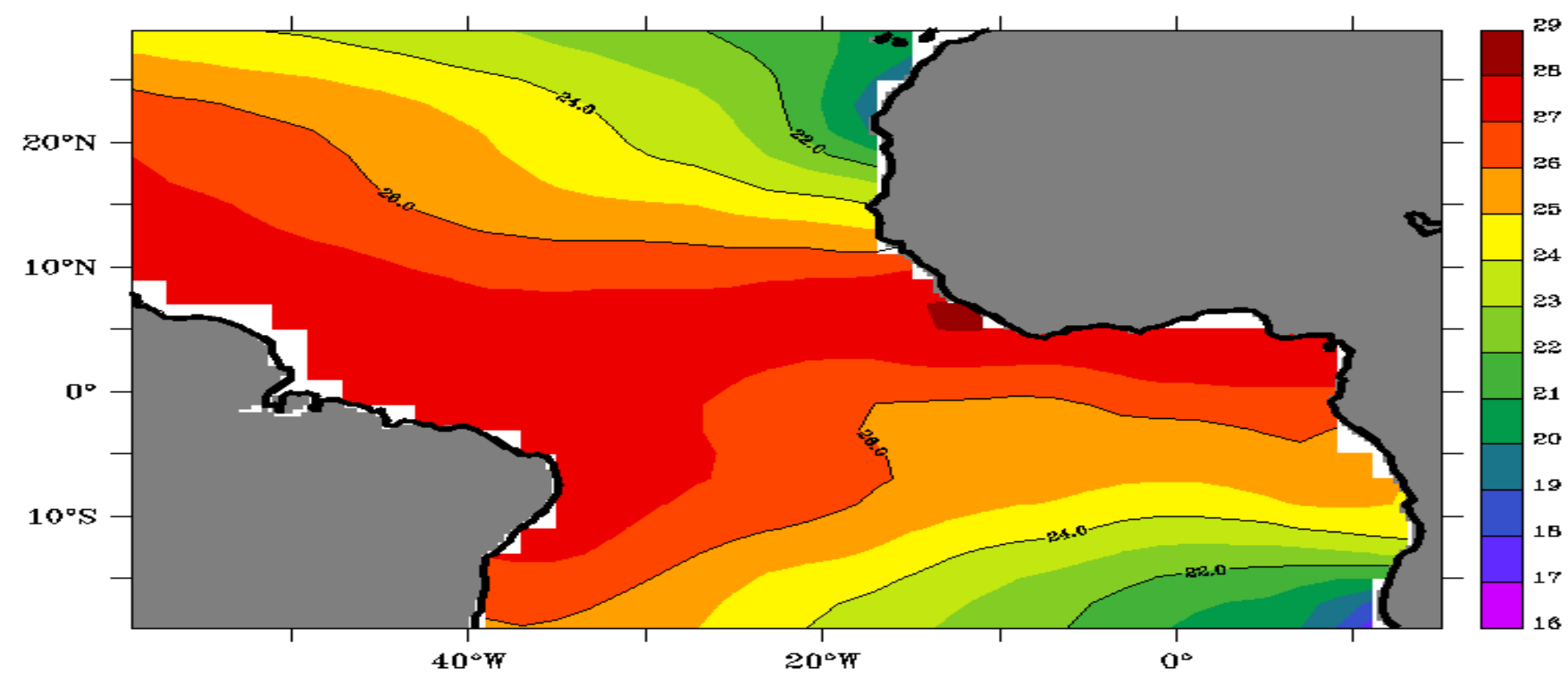

Fig. 1. 40-year (1964-2003) SST yearly climatology $\left({ }^{\circ} \mathrm{C}\right)$ (from Servain's data set: http://iridl.ldeo.columbia.edu/SOURCES/.SERVAIN/).

Also according to Servain (1991), the northern limit of NB $\left(28^{\circ} \mathrm{N}\right)$ and southern limit of SB $\left(20^{\circ} \mathrm{S}\right)$ are chosen in order to preserve equilibrium between the annual thermal changes of both hemispheric basins. The IHSST-mode index is calculated by doing the arithmetic difference between the normalized anomalies averaged over NB minus the normalized anomalies averaged over SB.

The monthly time series of such IHSST-mode index is given in Fig. 2a. It should be noted that this index is very close $(R=0.9)$ to the time-series of the second EOF mode computed from the SST anomalies. Both have been used in the past to describe the IHSST-mode. In addition to the raw monthly times series (Fig. 2a) and the wavelet analysis (Fig. 2b), three pass-band filtered time-series of the IHSSTmode can be seen. They are related to a $2-12$ month (Fig. 2c), 2-8 year (Fig. 2d) and 8-12 year (Fig. 2e) pass-band filters, respectively. The same procedure is applied to the ENSO index (here we chose the Global ENSO index), the NAO index (Hurrell et al. 2003), and the NEBR index (Nobre et al., 1988). These additional results are illustrated on Figs. 3, 4 , respectively. In the interest of brevity the corresponding figure for NEBR is not shown. The black contours on the wavelet representations (Figs. 2b, 3b, 4b) mark the significant region at 5\% confidence limit. Edge effects are important under the U-shaped thick black line. The panels at the right of each one of the wavelet representations show the global wavelet spectrum, with the confidence limit of 5\% assuming a red noise background.

\section{Results and conclusions}

The monthly time series of the IHSST-mode (blue line) and a 13-month running mean (red line) can be seen in Fig. 2a. Fig- ures $3 \mathrm{a}$ and $4 \mathrm{a}$ show similar plots for the other indices. From the wavelet analysis (Fig. 2b) it can be seen that the IHSSTmode presents significant changes in its low-frequency variance during the last 130 years. Despite the very significant peak around the 10-year period during the 1960-1980s (Fig. 2b), a natural oscillation at decadal time-scale along the IHSST-mode index time-series is not as clear as that discussed in the previous studies mentioned. The analysis of the decadal-scale, filtered time-series with 8-12 years bandpass (Fig. 2e), shows significant variance during three distinct periods: $1870-1890,1910-1920$ and 1965-1985. Indeed, this last period, widely referred to in the literature, shows the largest decadal signal. It should be noted that besides the decadal oscillation which is restricted to these three periods, the IHSST-mode spectrum presents significant oscillations of higher frequency ( 2 to 8 years) practically during all the study period (Fig. 2d). That is especially the case during the 1890 s years (e.g. note the rapid phase changes around the end of the 1880s in Fig. 2a). This last result must however be taken with caution because of the scarcity of observations during the last decades of the nineteen century. In order to examine the IHSST-mode decadal behavior relative to other climatic indices, wavelet analysis was also applied to the time-series associated with the NEBR (not shown), ENSO (Fig. 3) and the NAO (Fig. 4) indices.

The NE Brazil precipitation has been described (e.g. Wainer and Soares, 1997; Uvo et al., 1998) as strongly dependent on the ITCZ meridional shifts, and consequently linked to the variability of the IHSST-mode. At decadal time scales, only two periods of significant variance were observed with respect to the NEBR index: during 1870 to 1895 and 1965 to 1985 , matching two of the three decadal periods found for he IHSST-mode. Nonetheless, the decadal signal 


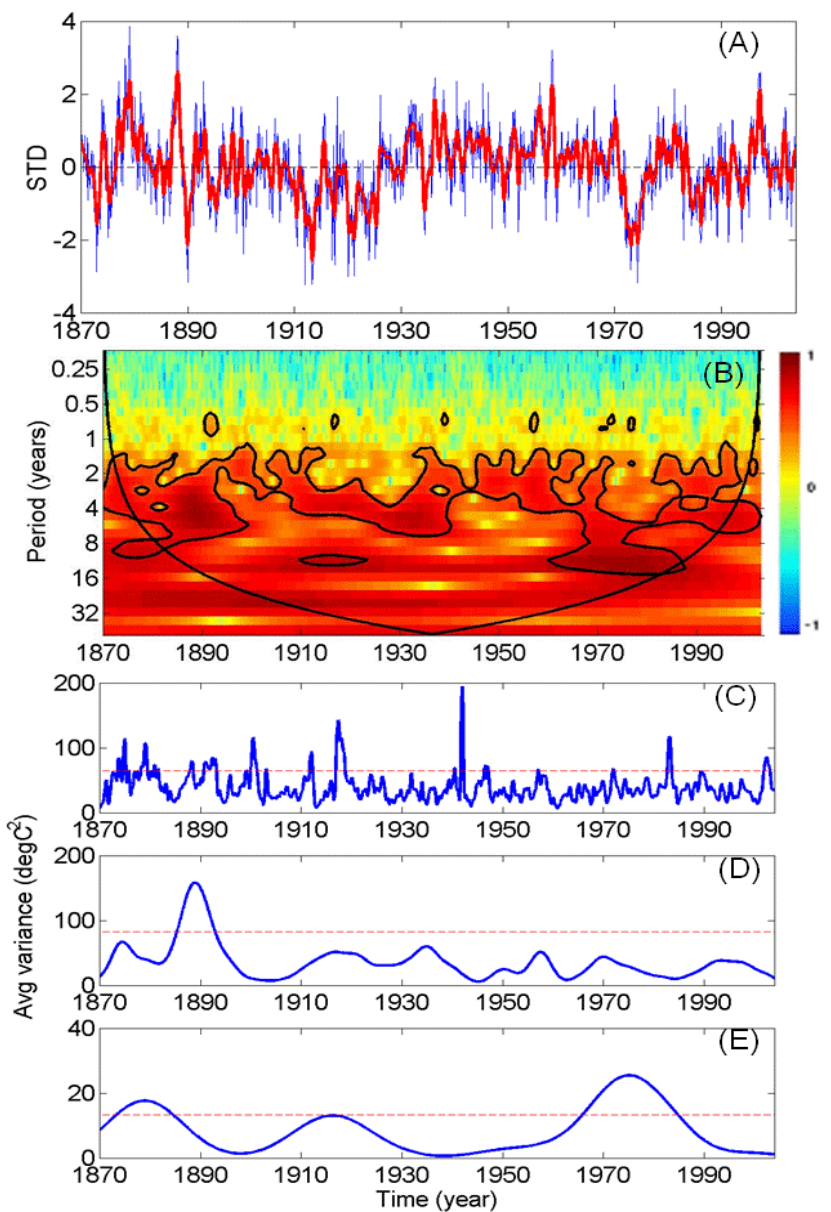

Fig. 2. IHSST-mode Analysis: (a) Monthly time series of the IHSST-mode index: The blue line shows the monthly data and the red line is a 13-month running mean; (b) wavelet spectrum: The black contours mark the significant region at $5 \%$ and the U-shaped huge black line delimits the region where the edge effects are important; (c), (d) and (e) The filtered time-series on seasonal, interannual and decadal time scales, respectively.

noted for the IHSST-mode during the 1910-1920s does not significantly appear on the NEBR index which is somewhat different from Wainer and Soares (1997) which had indicated that the relationship between SST and NBR was time-scale invariant.

The decadal signature is absent in the ENSO time series (Fig. 3a, e). The only significant period with such a decadal signal occurs in the 1880-1990s, but it could be again questionable due to the paucity of the data during that period. The prevailing frequencies in the tropical Pacific are around the 2-8 year period (Fig. 3d). These frequencies seem to be modulated by a very low-frequency oscillation of 20-40 years. Different from the ENSO signal, the NAO index shows an interesting decadal oscillation (Fig. 4e), especially during the 1880s, the 1920s, and the 1980-1990s. These three periods, with a preferred decadal signal, are roughly the same
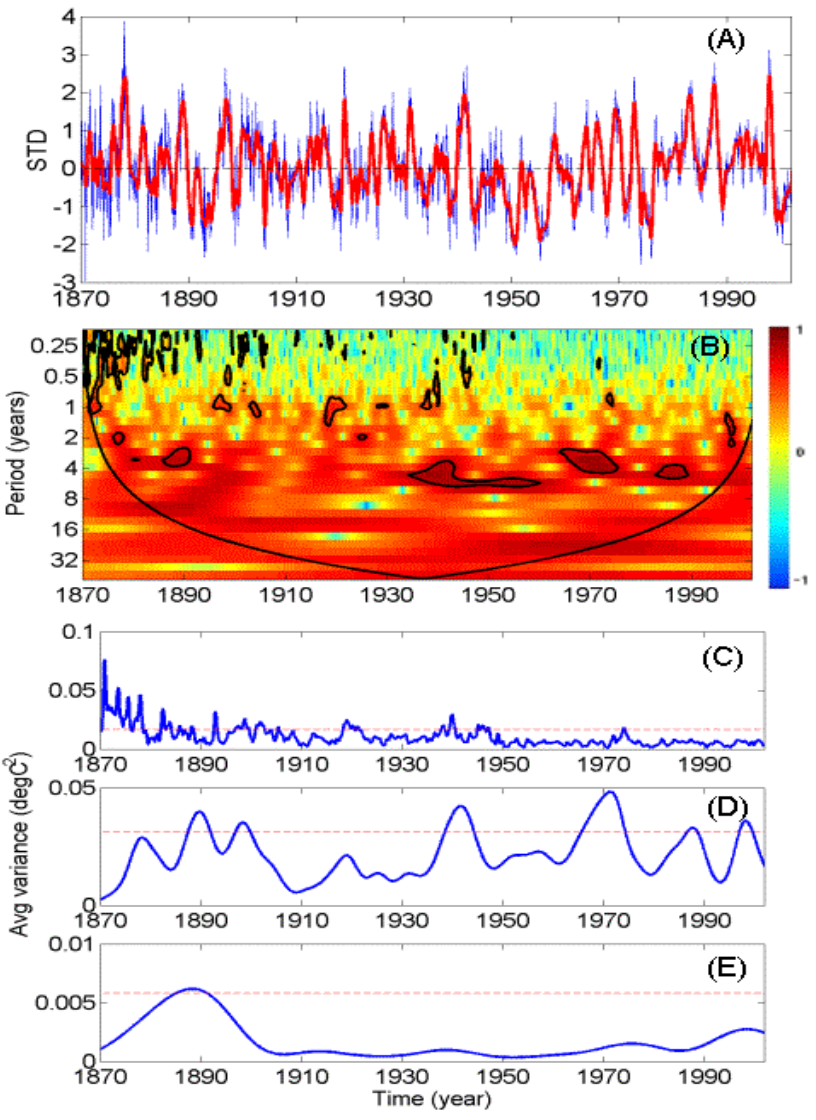

Fig. 3. El Nino/Southern Oscillation (ENSO) Analysis: (a) Monthly time series of the ENSO index: The blue line shows the monthly data and the red line is a 13-month running mean; (b) wavelet spectrum: The black contours mark the significant region at 5\% and the U-shaped huge black line delimits the region where the edge effects are important; (c), (d) and (e) The filtered time-series on seasonal, interannual and decadal time scales, respectively.

(with a lag of a few months) as the ones previously noted for the IHSST-mode (Fig. 2e). Indeed the two indices are well correlated as can be seen from Fig. 5. It shows the two standardized time series in the top panel (Fig. 5a) smoothed with a 5-year running mean in order eliminate higher frequency variability. Just looking at the superposition of the two time series it is evident that they are best anti-correlated within the periods we have identified for the prevalence of the decadal signal (1880s, the 1920s and 1970s). The 5-month lag observed with respect to the highest correlation coefficient $(-0.36)$, shown in Fig. 5 b, seems to indicate that this low-frequency oscillation first develops in the tropical latitudes of the Atlantic and then propagates polewards.

SST anomalies can be enhanced through wind-induced evaporation mechanism (WES) as described earlier, giving rise to the IHSST gradient. This in turn can induce (according to the model studies of Okumura et al., 2001) a barotropic teleconnection into the extratropics that projects 


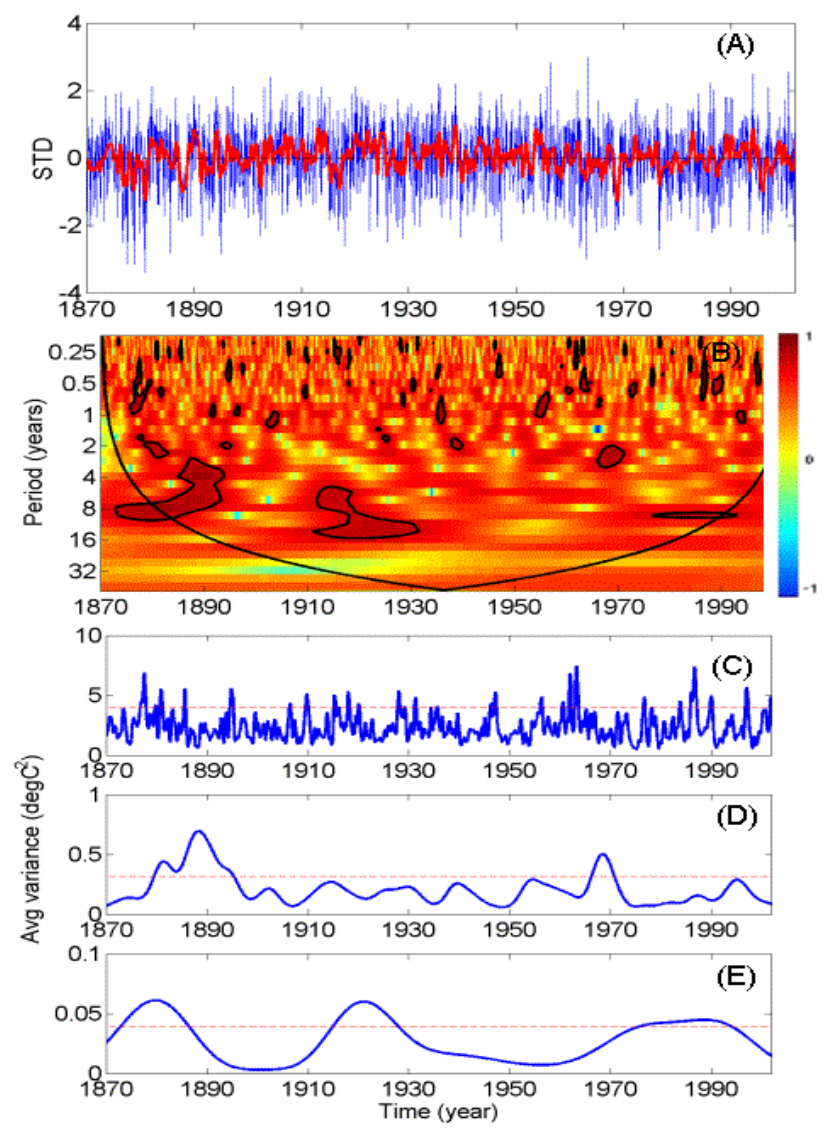

Fig. 4. North Atlantic Oscillation (NAO) Analysis: (a) Monthly time series of the NAO index: The blue line shows the monthly data and the red line is a 13-month running mean; (b) wavelet spectrum: The black contours mark the significant region at $5 \%$ and the Ushaped huge black line delimits the region where the edge effects are important; (c), (d) and (e) Variances of the filtered time-series on seasonal, interannual and decadal time scales, respectively.

onto the North Atlantic Oscillation (NAO). Previous studies suggested the reverse. For instance, Déqué and Servain (1989), Czaja et al. (2002), indicated that changes in the NAO could affect the subtropical high and associated lowlevel winds which would then impact on the SST distribution and consequently modify the related Nordeste rainfall.

Model studies performed by Wu et al. (2005) also show that SST anomalies for the North Atlantic can organize an inter-hemispheric SST dipole in boreal spring over both the tropical Atlantic and eastern tropical Pacific primarily through WES feedback which has already been discussed as being a key player in the growth and oscillation of this IHSST-mode. In fact, the proposed relationship between the NAO and the inter-hemispheric SST gradient could be related to the propagation of extratropical SST anomalies from the tropics through WES feedback. The WES feedback cannot only lead to a nearly synchronous change of tropical SST, but also force a delayed adjustment of the meridional overturning circulation in the upper ocean to further sustain the
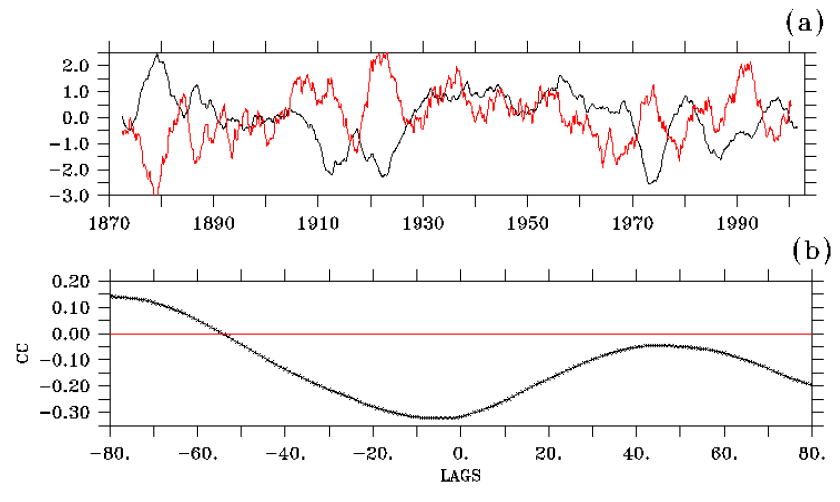

Fig. 5. (a) Standardized time series of the IHSST index (black) and NAO index (red) smoothed with a 5-year running mean; (b) Lagged correlation between the two time-series shown in (a). Correlation coefficients are significant at $95 \%$ and indicate the phase relationship (NAO lags IHSST). The highest correlation of -0.36 occurs at 5-months lag, with IHSST leading. Lags are in months.

tropical SST change as discussed by Wu et al. (2007) for the Pacific Ocean.

An interesting question is why and how such a decadal oscillation can develop. And why it can develop during some periods and not during others. It is likely that the origin of such a decadal oscillation could arise from non-linear interactive combination of local feedback air-sea process, remote influence of the Pacific ENSO, and other influences via planetary waves. However, even if it is assumed that the non-linear, stochastic nature of the interaction between the IHSST-mode and ENSO triggers the changes from one preferred frequency to the other, many questions remain unsolved. In any case, the important conclusion here is that the decadal variability of the IHSST-mode should be thought as episodic and not as a periodic oscillation.

In summary, the tropical Atlantic decadal mode of variability, which is largely documented and discussed in the literature, is prevalent only for part of the last 130-years record (the 1880s, the 1920s and, especially, the 1970s). This periodicity is evident in the tropical Atlantic basin (IHSST-mode index), the Northern Atlantic (NAO index), and possibly in the Nordeste Rainfall (NEBR index). It does not appear at all in the Pacific (except perhaps during the poorly data documented 1880 s period). Furthermore, decadal variability associated with the IHSST gradient-mode is correlated, with a 5 -month lag to the decadal variability associated to the NAO.

Acknowledgements. This work was supported in part by grants from FAPESP, CNPq, and IRD-CNPq (CATIN).

Topical Editor S. Gulev and the authors thank two anonymous referees for their help in evaluating this paper. 


\section{References}

Ayina, L. H. and Servain, J.: Spatial-temporal evolution of the low frequency climate variability in the tropical Atlantic, in: Interhemispheric Water Exchange in the Atlantic Ocean (Elsevier Oceanographic Series), edited by: Goni, G. J. and MalanotteRazzoli, P., 475-495, 2003.

Bourlès, B., Lumpkin, R., McPhaden, M. J., Campos, E., Hernandez, F., Nobre, P., Planton, S., Yu, L., Busalacchi, A. J., Moura, A. D., Servain, J., and Trotte, J.: The PIRATA Program: History, Accomplishments, and Future Directions, B. Am. Meteorol. Soc., 89(8), 1111-1125, 2008.

Czaja, A., van der Vaart, P., and Marshall, J.: A diagnostic study of the role of remote forcing in tropical Atlantic variability, J. Climate, 15, 3280-3290, 2002.

Chang, P., Ji, L., and Li, H.: Decadal climate variation in the tropical Atlantic Ocean from thermodynamic air-sea interactions, Nature, 385, 516-518, 1997.

Chu, P.-S.: Time and space variability of rainfall and surface circulation in the northeast Brazil-tropical Atlantic sector, J. Meteorol. Soc. Jpn., 26, 363-369, 1984.

Delworth, T. L. and Mehta, V. M.: Simulated interannual to decadal variability in the tropical and sub-tropical Atlantic, Geophys. Res. Lett., 25, 2825-2828, 1998.

Déqué, M. and Servain, J.: Teleconnections between tropical Atlantic sea surface temperatures and midlatitude $50 \mathrm{KPa}$ heights during 1964-1986, J. Climatol., 2, 929-944, 1989.

Hastenrath, S. and Lamb, P.: Climatic Atlas of the Tropical Atlantic and Eastern Pacific Oceans, University of Wisconsin Press, 113 pp, 1977.

Hastenrath, S. and Heller, L.: Dynamics of climate hazards in Northeast Brazil, Q. J. Roy. Meteorol. Soc., 103, 77-92, 1997.

Hastenrath, S. and Kaczmarczyk, E. B.: On spectra and coherence of tropical climate anomalies, Tellus, 33, 453-462, 1981.

Huang, B. H., Schopf, P. S., and Shukla, J.: Intrinsic oceanatmosphere variability of the variability of the tropical of the tropical Atlantic Ocean, J. Climate., 17, 2058-2077, 2004.

Hurrell, J. W., Kushnir, Y., Ottersen, G., and Visbeck, V.: The North Atlantic Oscillation: Climate significance and environmental impact, Geophys. Mono. Series, 134, 279 pp, 2003.

Mehta, V. M. and Delworth, T. L.: Decadal variability of the tropical Atlantic Ocean surface temperature in shipboard measurements and in a global ocean-atmosphere model, J. Climate, 8, 171-190, 1995.

Mehta, V. M.: Variability of the Tropical Ocean Surface Temperatures at Decadal-Multidecadal Timescales. Part I: The Atlantic Ocean, J. Climate, 11, 2351-2375, 1998.

Moura, A. D. and Shukla, J.: On the dynamics of droughts in the northeast Brazil: Observations, theory and numerical experiments with a general circulation model, J. Atmos. Sci., 38, 26532675, 1981.

Murtugudde, R. G., Ballabrera-Poy, J., Beauchamp, J., and Busalacchi, A. J., Relationship between zonal and meridional modes in the tropical Atlantic, Geophys. Res. Lett., 28(23), 4463-4466, 2001.

Nobre, P. and Shukla, J.: Variations of sea surface temperature, wind stress and rainfall over the tropical Atlantic and South America, J. Climate, 9, 2464-2479, 1996.
Nobre, C. A. and Molion, L. C. B.: The climatology of droughts and drought prediction. The Impact of Climatic Variations on Agriculture, Assessments in Semi-Arid Regions, edited by: Parry, M., Carter, T. R., and Konijn, N. T., Kluwer Academic, 305-323, 1988.

Okumura, Y., Xie, S.-P., Numaguti, A., and Tanimoto, Y.: Tropical Atlantic air-sea interaction and its influence on the NAO, Geophys. Res. Lett., 28, 1507-1510, 2001.

Penland, C. and Matrosova, L.: Prediction of tropical Atlantic sea surface temperatures using linear inverse modeling, J. Climate, 11, 483-496, 1998.

Servain, J.: Simple climatic indices for the tropical Atlantic Ocean and some applications, J. Geophys. Res., 96, 15137-15146, 1991.

Servain, J. and Merle, J.: Interannual climate variations over the tropical Atlantic Ocean, NATO- V, 16, 153-171, 1993.

Servain, J., Wainer, I, McCreary, J. P., and Dessier, A.: Relationship between the equatorial and meridional modes of climatic variability in the tropical Atlantic, Geophys. Res. Lett., 26(4), 485-488, doi:10.1029/1999GL900014, 1999.

Servain, J., Clauzet, G., and Wainer, I.: Modes of tropical Atlantic variability observed by PIRATA, Geophys. Res. Lett., 30(5), 8003, doi:10.1029/2002GL015124, 2003.

Servain, J. and Legler, D. M.: Empirical orthogonal function analyses of tropical Atlantic sea surface temperature and wind stress: 1964-1979, J. Geophys. Res., 91, 14181-14191, 1986.

Servain, J. and Lukas, S.: Climatic Atlas of the tropical Atlantic wind stress and sea surface temperature 1985-1989, edited by: l'IFREMER, SDP, BP 70, 29280 Plouzané, 146 pp., 1990.

Smith, T. M. and Reynolds, R. W.: Improved extended reconstruction of SST (1854-1997), J. Climate, 17, 2466-2477, 2004.

Tanimoto, Y. and Xie, S. P.: Ocean-atmosphere variability over the Pan-Atlantic basin, J. Meteorol. Soc. Japan, 77, 31-46, 1999.

Torrence, C. and Compo, G. P.: A practical guide to wavelet analysis, B. Am. Meteorol. Soc., 79, 61-78, 1998.

Uvo, C., Repelli, C., Zebiak, S. E., and Kushnir, Y.: The Relationships between Tropical Pacific and Atlantic SST and Northeast Brazil Monthly Precipitation, J. Climate, 11, 551-562, 1998.

Wagner, R. G.: Decadal-scale trends in mechanisms controlling meridional sea surface temperature gradients in the tropical Atlantic, J. Geophys. Res., 101, 16683-16694, 1996.

Wainer, I. and Soares, J.: North Northeast Brazil Rainfall and its Decadal-Scale Relationship to Wind Strees and Sea Surface Temperature, Geophys. Res. Lett., 24, 277-280, 1997.

Wu, L., Liu, Z., Li, C., and Sun, Y.: Extratropical control of recent tropical Pacific decadal climate variability: A relay teleconnection, Clim. Dynam., 28, 99-112, 2007.

Wu, L., He, F., and Liu, Z.: Coupled ocean-atmosphere response to north tropical Atlantic SST: Tropical Atlantic dipole and ENSO, Geophys. Res. Lett., 32, L21712, doi:10.1029/2005GL024222, 2005.

Xie, S.-P. and Philander, S. G. H.: A coupled ocean-atmosphere model of relevance tothe ITCZ in the eastern Pacific, Tellus, 46A, 340-350, 1994.

Xie, S. P.: A dynamic ocean-atmosphere model of the tropical Atlantic decadal variability, J. Climate, 12(1), 64-70, 1999.

Zebiak, S. E.: Air-Sea interaction in the equatorial Atlantic region, J. Climate, 6, 1567-1586, 1993. 